\title{
The effect of prolonged standing on the body and the impact of footwear hardness
}

\author{
Jennifer Anderson, Christopher J Nester, Anita E Williams \\ School of Health Sciences, University of Salford
}

\section{Introduction}

Prolonged standing is an occupational feature for around half of all workers. Risk of musculoskeletal disorders of the lower back, lower extremities and feet is increased in this population (Andersen et al., 2007).

Softer flooring with greater elasticity and decreased energy absorption has been associated with decreases in subjective discomfort (Cham and Redfern, 2001). Footwear and insoles have also been shown to influence discomfort during prolonged standing (Orlando and King, 2002) and have the advantage of being individual and portable.

However, the effect of prolonged standing and interventions on lower limb biomechanical parameters is not fully understood (Waters and Dick, 2016). Further, no research has investigated the effect of altering individual footwear parameters on the biomechanics of prolonged standing.

\section{Purpose of the study}

The purpose of this study was to investigate the impact of prolonged standing on the body and determine the impact of altering footwear density.

\section{Methods}

Twelve participants (male: 6, female: 6, age: $28 \pm 5$ years; weight $68 \pm 11 \mathrm{~kg}$; height: $1.7 \pm$ $0.1 \mathrm{~m}$ ) attended 2 sessions, 24 hours apart in which they stood for 3 hours whilst completing a series of continuous simulated stationary work tasks. These required standing and only minor shuffling of feet. Two versions (hard / soft) of surgical footwear were tested, manufactured from the same molds (Table 1). Participants were blind to this difference.

Every 30 minutes within the 3 hour task, subjective discomfort on a visual analogue scale and calf circumference were measured. According to a pre-determined schedule the same tasks were completed every 30 minutes and biomechanical data was collected during a stationary manual task and a task that involved weight shifting as objects were moved, but without stepping.

\begin{tabular}{|c|c|c|c|}
\hline \multicolumn{2}{|r|}{ Criteria } & $\begin{array}{c}\text { Softer } \\
\text { shoe }\end{array}$ & $\begin{array}{c}\text { Harder } \\
\text { shoe }\end{array}$ \\
\hline \multicolumn{2}{|c|}{ Hardness (cellular - Shore A/3s) } & 34 & 38 \\
\hline \multicolumn{2}{|c|}{ Hardness (compact - Shore A/3s) } & 76 & 69 \\
\hline \multicolumn{2}{|c|}{ Density (cellular $\mathbf{g} / \mathrm{cm}^{3}$ ) } & 0.22 & 0.20 \\
\hline \multicolumn{2}{|c|}{ Energy Absorption (J) } & 31.2 & 34.2 \\
\hline \multirow{3}{*}{$\begin{array}{l}\text { Shock } \\
\text { absorption }\end{array}$} & Deceleration $\left(\mathrm{m} / \mathrm{s}^{2}\right)$ & 100 & 120 \\
\hline & Penetration (mm) & 8.0 & 6.5 \\
\hline & \% energy return & 32 & 29 \\
\hline
\end{tabular}

Kinematic $(100 \mathrm{~Hz}$, Vicon), force plate (one foot/plate) $(1500 \mathrm{~Hz}$, Kistler) and in-shoe pressure data $(50 \mathrm{~Hz}$, Pedar) were measured.

A two-way within subject ANOVA with Bonferroni post hoc was used, with a significance level of 0.05 (SPSS).

Table 1. Difference in tested footwear

\section{Results}

Over time, increases in discomfort for all regions (whole body, lower back, upper leg, knee, calf, ankle and foot) were found for both shoes $(\mathrm{p}<0.05)$. Ratings of shoe sole hardness increased over time $(p<0.05)$ but did not differ 
between shoes. The increase in low back discomfort was greater in the harder shoe $(\mathrm{p}=$ 0.047).

Calf circumference also increased throughout $(\mathrm{p}<0.001)$, the center of pressure shifted laterally and internal ankle inversion moment increased $(\mathrm{p}<0.001)$. Whole foot and heel plantar pressure increased over time (mean pressure, max pressure, contact area and PTI $(\mathrm{p}<0.05))$.

There was an interaction (i.e. shoe) effect for the mean pressure of the whole foot over time $(\mathrm{p}=0.047)$, with the softer shoe increasing pressure at a greater rate. However, the absolute values did not differ between shoes as the softer shoe started with a lower mean pressure value.

Eight of the participants identified a preferred shoe (5 softer, 3 harder). The preferred shoe had a greater medial midfoot contact area $(\mathrm{p}=0.04)$ and a greater internal inversion moment $(\mathrm{p}=0.004)$.

\section{Discussion and Conclusion}

Prolonged standing increases numerous variables related to musculoskeletal disorders.

Despite only small variances between the tested footwear, associated lower back discomfort and in-shoe pressure changes were observed between the shoes.

Large standard deviations indicate individuals react differently over time and between shoes. Despite no subjective differences in the shoe hardness, two thirds of participants stated a shoe preference with preferred shoes having a greater medial foot contact area and an increased internal inversion moment.

This study reinforces the need to use strategies to support musculoskeletal performance in workplaces that demand prolonged standing. It has demonstrated footwear hardness affects biomechanical variables and appears to be related to footwear comfort and preferences. Future research must investigate the effect of footwear design parameters on standing as well as to focus on the effect of individual differences.

\section{References}

Andersen, J.H. et al. (2007). Arthritis Rheum, 56, 1355-1364.

Cham, R. and M.S. Redfern. (2001). Hum Factors, 43(3), 381-391

Orlando, A.R., and P.M. King. (2004). J Occup Rehabil, 14(1), 63-76.

Waters, T.R. and R.B. Dick. (2015). Rehabil Nurse, 40(3), $148-165$. 